\title{
Correction to: QTL analysis reveals genomic variants linked to high-temperature fermentation performance in the industrial yeast
}

\author{
Zhen Wang ${ }^{1,2+}$, Qi Qi ${ }^{1,2+}$, Yuping Lin ${ }^{1 *}$, Yufeng Guo ${ }^{1}$, Yanfang Liu ${ }^{1,2}$ and Qinhong Wang ${ }^{1 *}$
}

\section{Correction to: Biotechnol Biofuels (2019) 12:59}

https://doi.org/10.1186/s13068-019-1398-7

Shortly after publication of the original article [1], the authors noticed a few errors which are outlined below:

In Table 2, the SNP mutation for RXT2 in ScY01 $\alpha$-tp should be $331 \mathrm{C}>\mathrm{G}$. As shown in Additional file 5: Dataset S3, the position of the SNP in RXT2 is NC_001134.8:435,368, and annotated as G>C according to the chromosome sequence. Since the coding sequence of RXT2 (systematic gene name: YBR095C) is on the Crick strand, the SNP should be described as $\mathrm{C}>\mathrm{G}$ at the 331 position according to the coding sequence. The corrected Table 2 is provided here.

The gene ECM24, which was misspelled six times in the original article, should be ECM22 in the following contents: the Abstract, the last paragraph of the Background,

Table 2 Genes with nonsynonymous variants in two major and two minor QTLs

\begin{tabular}{|c|c|c|c|c|c|c|c|c|}
\hline \multirow[t]{2}{*}{ QTLs } & \multirow[t]{2}{*}{ Chr } & \multirow[t]{2}{*}{ Start (bp) } & \multirow[t]{2}{*}{ End (bp) } & \multirow[t]{2}{*}{ Length (bp) } & \multirow[t]{2}{*}{ LOD score } & \multirow[t]{2}{*}{ Affected gene } & \multicolumn{2}{|c|}{ Mutation ( $\mathrm{S} 288 \mathrm{c}$ genome as a reference) } \\
\hline & & & & & & & ScY01a-tp & W65a-sp \\
\hline \multicolumn{9}{|c|}{ Major QTLs } \\
\hline \multirow[t]{2}{*}{ QTL1 } & $\|$ & 408,800 & 553,700 & 144,900 & 17 & RXT2 & $331 \mathrm{C}>\mathrm{G}(\mathrm{R} 111 \mathrm{G})$ & Wild type \\
\hline & & & & & & VID24 & $154 \mathrm{C}>\mathrm{T}(\mathrm{P} 52 \mathrm{~S})$ & Wild type \\
\hline \multirow[t]{3}{*}{ QTL2 } & $X \|$ & 595,800 & 633,500 & 37,700 & 300 & ECM22 & 1954 G>A (G652S) & Wild type \\
\hline & & & & & & VPS34 & $1773 C>G(D 591 E)$ & Wild type \\
\hline & & & & & & $\mathrm{CSCl}$ & $1126 \mathrm{C}>\mathrm{A}(\mathrm{Q} 376 \mathrm{~K})$ & Wild type \\
\hline \multicolumn{9}{|c|}{ Minor QTLS } \\
\hline \multirow[t]{2}{*}{ QTL3 } & $X V$ & 174,500 & 184,900 & 10,400 & 272 & IRA2 & Wild type & $7222 \mathrm{C}>\mathrm{A}(\mathrm{P} 2408 \mathrm{~T})$ \\
\hline & & & & & & AVO1 & Wild type & $2558 \mathrm{~T}>\mathrm{C}(\mathrm{V} 853 \mathrm{~A})$ \\
\hline QTL4 & $X \mathrm{VI}$ & 228,200 & 238,100 & 9900 & 155 & DAP1 & Wild type & 115 G>A (V39I) \\
\hline
\end{tabular}

\footnotetext{
*Correspondence: lin_yp@tib.cas.cn; wang_qh@tib.cas.cn

†Z Zhen Wang and Qi Qi contributed equally to this work

${ }^{1}$ CAS Key Laboratory of Systems Microbial Biotechnology, Tianjin Institute of Industrial Biotechnology, Chinese Academy of Sciences, Tianjin 300308,

China

Full list of author information is available at the end of the article
} 
sentence 5 and 6 in paragraph 1 under the heading "Characterization of key causative gene alleles for improving high-temperature fermentation of the industrial yeast", the last paragraph of the Discussion and the Conclusions.

Page 11, paragraph 3 under the heading "Characterization of key causative gene alleles for improving high-temperature fermentation of the industrial yeast", sentence 8 should be: "By contrast, membrane fluidities of these cells at the stationary phase among the reciprocal hemizygotes of DAP1 and the control strains were similar."

In the following two contexts, the word "thermosensitive" should be "thermotolerant". Page 4, paragraph 2 under the heading "Screening of the superior, inferior and random pools of segregants for genome sequencing", sentence 7 should be: "Thus, ten segregants showing the 10 highest $\mathrm{OD}_{600}$ ratios (1.37 to 2.17) than ScY01 $\alpha$-tp were selected as the most thermotolerant segregants and assembled in the superior pool." Sentence 3 in the Fig. 3b legend should be: "Ten segregants showing the 10 highest $\mathrm{OD}_{600}$ ratios (1.37 to 2.17) than ScY01 $\alpha$-tp were selected as the most thermotolerant segregants and assembled in the superior pool."

In sentence 2 of the Fig. 4 legend, the strain name "W65a-tp" should be "W65a-sp". In sentence 4 of the Fig. 4 legend, the Ref. [30] should be [25].

Page 14, Methods paragraph 2, sentence 5 should be: "Starting $\mathrm{OD}_{600}$ used in all the experiments was 0.5."

The description "(hours 0, 8, 12, 18, 24 303642 and 48 )" should be "(hours $0,4,8,12,18,24,30,36,42$ and
$48)$ " in the following two contents: sentence 1 in the Fig. 6 legend and sentence 5 in the last paragraph of the Methods.

These changes will in no manner affect the outcome/ interpretation of the experiments as described in the original publication. The authors apologize for any inconvenience caused.

\section{Author details}

${ }^{1}$ CAS Key Laboratory of Systems Microbial Biotechnology, Tianjin Institute of Industrial Biotechnology, Chinese Academy of Sciences, Tianjin 300308, China. ${ }^{2}$ University of Chinese Academy of Sciences, Beijing 100049, China.

The original article can be found online at https://doi.org/10.1186/s1306 8-019-1398-7

\section{Publisher's Note}

Springer Nature remains neutral with regard to jurisdictional claims in published maps and institutional affiliations.

Received: 30 November 2018 Accepted: 8 April 2019

Published online: 10 April 2019

\section{Reference}

1. Wang Z, Qi Q, Lin Y, Guo Y, Liu Y, Wang Q. QTL analysis reveals genomic variants linked to high-temperature fermentation performance in the industrial yeast. Biotechnol Biofuels. 2019;12:59. https://doi.org/10.1186/ s13068-019-1398-7. 